\title{
Features of the choice of power unit for electric tricycle
}

\author{
Dmitry Stakhin ${ }^{1, *}$, Kirill Goncharov ${ }^{2}$ \\ ${ }^{1}$ Peter the Great St. Petersburg Polytechnic University, St. Petersburg, Russian Federation \\ ${ }^{2}$ Nizhniy Novgorod State Technical University n.a. R.E. Alekseev, Nizhny Novgorod, Russian Federation
}

\begin{abstract}
The article considers the bolide Shell Eco Marathon, which main operating purpose is to cover the maximum distance with the minimum fuel consumption. With the aim of providing the bolide with technical and operational indicators, it is appropriate to solve the problem of decreasing the bolide's mass, the air drag coefficient, and also the choice of the economic power plant. The basic formulas for the engine traction-dynamic calculation are presented. Due to the results of the calculation, the conclusion about profitability of the power plant is made. There is also a description of the principle of the electric engine and its main advantages comparing to the internal combustion engines.
\end{abstract}

\section{Introduction}

Shell Eco-Marathon minimum fuel consumption car competitions are held all over the world. For the first time this marathon was held by Shell oil company in 1939. Since then, it has been held annually. The main purpose of the competition is to cover the maximum distance only on the one liter of fuel. In 1985 the winner of the Eco-Marathon car got a result that showed a possibility of driving the distance from Rotterdam to London only on the 1 liter of fuel. 30 years later, the prototype, working on the compressed natural gas (CNG), of the French team Microjoule La Joliverie had driven on the 1 liter of fuel $2551.8 \mathrm{~km}$, that is equal to the distance from Rotterdam to Moscow, and generally showed the best result of 2016.

Today, the decrease of the air pollution toxic substances, that is emitted by the industrial enterprises and transport vehicles, is one of the most essential tasks for car manufacturers [1,2]. 40 percent of the entire air pollution is made by the road transport. The average car emits 135 kilograms of carbon monoxide, 25 kilograms of nitrogen oxides, 20 kilograms of hydrocarbons, 7 to 10 kilograms of benzopyrene, 4 kilograms of sulfur dioxide and 1.2 kilograms of solid particles per year. [3-5].

Today, there are about 500 million cars in the world. Together they emit 67.5 megatons of carbon monoxide and 12.5 megatons of nitrogen oxides every year [6]. The most promising alternative to the internal combustion engine is an electric engine. One of the main limitations of the widespread introduction of the electric vehicles is the small battery life. [7, 8]. Batteries used in electric vehicles are not sufficiently adapted to low and high temperatures and have a limited number of charge/discharge cycles. [9-11].

\section{Methods}

\footnotetext{
* Corresponding author: dimka.sta777@gmail.com
}

During the design of the tricycle (Fig. 1), a number of studies were carried out. In order to determine the shape of the body with minimal air resistance, several variants of the monocoque design are proposed, based on the layout and technical solutions of the chassis. For the tricycle model, the coordinate of the center of mass was calculated. To do this, the 3D model of the tricycle in the Autodesk Inventor program determined the coordinates of the main parts of the car (frame, battery, steering) and the pilot on the axes (table 1) (Fig. 2).

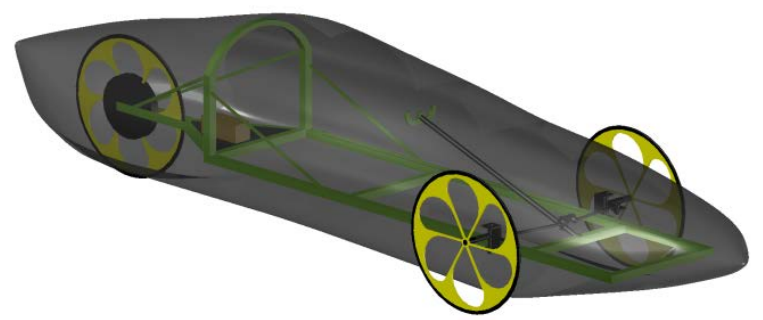

Fig. 1 General view of the bolide Shell Eco-Marathon

Due to the lack of suspension, the sprung mass includes the motor-wheel and driven wheels, excluding tires.

Let us determine the coordinates of the center of mass of the system by the relations:

$$
x_{c}=\frac{\sum m i * x i}{\sum m i} y_{c}=\frac{\sum m i * y i}{\sum m i}, \quad \text { where (1) }
$$

$\mathrm{i}$ - the sequence number of the element specified in the table 1;

$\mathrm{m}$ - the mass of an element;

$\mathrm{x}_{\mathrm{c}}, \mathrm{y}_{\mathrm{c}}$ - the coordinates of the center of mass on the $\mathrm{x}$ and y axis, respectively.

Table 1. Source data.

\begin{tabular}{|c|c|c|c|c|}
\hline № & Element & $\begin{array}{c}\text { Weight, } \\
\mathrm{kg}\end{array}$ & $\begin{array}{c}\text { The } \mathrm{x}- \\
\text { coordinate } \\
\mathrm{m}\end{array}$ & $\begin{array}{c}\text { The } \mathrm{y}- \\
\text { coordinate, } \\
\mathrm{m}\end{array}$ \\
\hline 1 & Pilot & 75 & 0.751 & 0.129 \\
\hline 2 & Frame & 20 & 1.178 & 0 \\
\hline 3 & Storage & 10 & 1.590 & 0.04 \\
\hline
\end{tabular}




\begin{tabular}{|c|c|c|c|c|}
\hline & battery & & & \\
\hline 4 & $\begin{array}{c}\text { Steering } \\
\text { system }\end{array}$ & 3 & -0.93 & 0.05 \\
\hline 5 & $\begin{array}{c}\text { Motor- } \\
\text { wheel }\end{array}$ & 7 & 2.11 & 0 \\
\hline 6 & $\begin{array}{c}\text { Driven } \\
\text { wheels }\end{array}$ & 3 & 0 & 0.03 \\
\hline
\end{tabular}

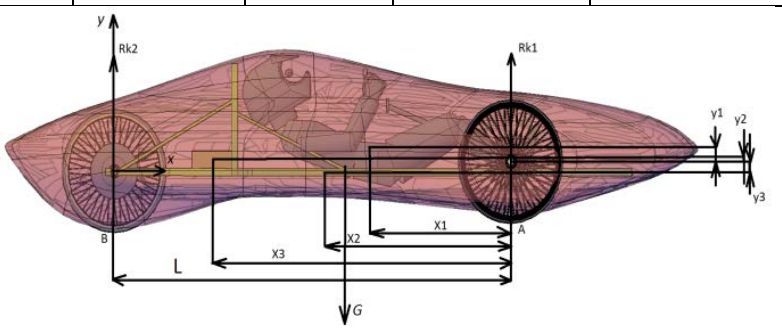

Fig. 2 Determination of the center of mass of the car

Enter the calculated data in table 2.

Table 2. The coordinates of the center of mass.

\begin{tabular}{|c|c|c|c|c|c|}
\hline № & $\mathrm{m}_{\mathrm{i}}, \mathrm{kg}$ & $\mathrm{m}_{\mathrm{i}} \bullet \mathrm{X}_{\mathrm{i}}$ & $\mathrm{m}_{\mathrm{i}} \bullet \mathrm{y}_{\mathrm{i}}$ & $\begin{array}{c}\mathrm{X}_{\mathrm{c}} \\
\mathrm{m}\end{array}$ & $\begin{array}{c}Y_{\mathrm{c}} \\
\mathrm{m}\end{array}$ \\
\hline 1 & 75 & 56.325 & 9.675 & \multirow{7}{*}{0.913} & \multirow{7}{*}{0.005} \\
\hline 2 & 20 & 23.56 & 0 & & \\
\hline 3 & 10 & 15.9 & 0.4 & & \\
\hline 4 & 3 & -2.79 & 0.15 & & \\
\hline 5 & 7 & 14.805 & 0 & & \\
\hline 6 & 3 & 0 & 0.09 & & \\
\hline Summ & 118 & 107.8 & 0.64 & & \\
\hline
\end{tabular}

For a more competent placement of the components of the car, it is necessary to calculate the normal load on the front and rear wheels. In the future, this will help determine how accurately the vehicle units have been placed, as the ideal ratio between axle load distribution is a 50: 50 ratio between the wheels.

Calculate the normal load $\mathrm{R}_{\mathrm{K} 1}(\mathrm{~N})$, acting on the front axle of the car, from the equation of the moments of the acting forces relative to the axis of the rear wheels:

$$
\begin{gathered}
\sum \mathrm{M}\left(\mathrm{R}_{\mathrm{k} 2}\right)=0 \\
\mathrm{G} \cdot \mathrm{Xc}-\mathrm{R}_{\mathrm{k} 1} \cdot \mathrm{L}=0 \\
\mathrm{R}_{\mathrm{k} 1}=\mathrm{G} \cdot \mathrm{Xc} / \mathrm{L}=\mathrm{m} \bullet \mathrm{g} \cdot \mathrm{Xc} / \mathrm{L}=118 \cdot 9.81 \bullet 0.913 / 2.11 \\
=500.9 \mathrm{~N}
\end{gathered}
$$

Calculate the normal load $\mathrm{R}_{\mathrm{K} 2}(\mathrm{H})$, acting on the rear wheel of the car, from the equation of the moments of the acting forces relative to the axis of the front:

$$
\begin{gathered}
\sum \mathrm{M}\left(\mathrm{R}_{\mathrm{k} 1}\right)=0 \\
\mathrm{R}_{\mathrm{k} 2} \bullet \mathrm{L}-\mathrm{G} \bullet(\mathrm{L}-\mathrm{Xc})=0 \\
\mathrm{R}_{\mathrm{k} 2}=\mathrm{G} \bullet(\mathrm{L}-\mathrm{Xc}) / \mathrm{L}=\mathrm{m} \bullet \mathrm{g} \bullet(\mathrm{L}-\mathrm{Xc}) / \mathrm{L}=118 \bullet 9.81 \\
(2.11-0.913) / 2.11=656.7 \mathrm{~N}
\end{gathered}
$$

From calculations in sight, that greater burden perceives leading rear wheel, which should provide the absence of slippage between wheel and's surface during start tricycle.

Analysis of existing electric motors on the market showed that their dimensions and weight are too large for installation on an economical car. In this regard, it was decided to pay attention to the motor-wheels (Fig. 3 ), which are not less powerful, but more economical and lightweight, as well as more adapted to the

movement of vehicles. Included with the motor wheel (Fig. 4) is a microcontroller, which will ensure the interconnection of the components and allow you to set the necessary parameters of the traction torque of the engine. Thanks to the use of an electric motor, the braking recovery system will be activated during braking, which will increase the power reserve of the car.

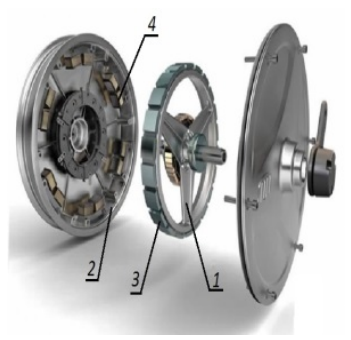

Fig. 3 Schematic diagram motor wheel

1-stator, 2-rotor, 3magnets, 4-windings.

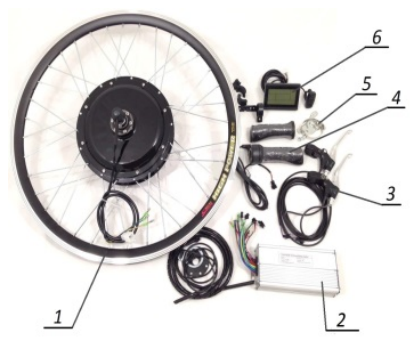

Fig.4 Motor-wheel set 1-spoke, motor-wheel, 2controller, 3-brake knobs, 4-gas knobs, 5-dropout amplifiers, 6control panel.

In order to obtain optimal traction and dynamic characteristics of the three cycles and the selection of the electric motor, we perform traction and dynamic calculation [12]. The initial data for the traction calculation are shown in table 3.

Table 3. Source data for the traction calculation.

\begin{tabular}{|c|c|c|}
\hline Paremetrs & $\begin{array}{c}\text { Table of } \\
\text { symbols }\end{array}$ & Values \\
\hline Power, $\mathrm{kW}$ & $\mathrm{Pe}$ & 1 \\
\hline Moment, $\mathrm{N} \cdot \mathrm{m}$ & $\mathrm{Te}$ & 30 \\
\hline Gross weight, $\mathrm{kg}$ & $\mathrm{m}$ & 110 \\
\hline Overall height, $\mathrm{m}$ & $\mathrm{H}$ & 1.225 \\
\hline Overall width, $\mathrm{m}$ & $\mathrm{B}$ & 0.5 \\
\hline $\begin{array}{c}\text { Transmission } \\
\text { efficiency }\end{array}$ & $\mathrm{H}_{\mathrm{tr}}$ & 0.9 \\
\hline Wheel radius, $\mathrm{m}$ & $\mathrm{r}_{\mathrm{d}}$ & 0.3 \\
\hline
\end{tabular}

\section{Results and Discussion}

The external speed characteristic of the electric motor is built. To do this, we divide the entire range of angular velocity values into 10 equal parts. Setting the nominal torque of the engine (Te), determine its maximum power $(\mathrm{Pe})$. Next, determine the power value for each angular velocity value (Table 4). Build a chart of the external speed characteristics (Fig. 5).

Table 4. Source data for the external speed characteristics

\begin{tabular}{|c|c|c|}
\hline $\begin{array}{c}\text { Angular } \\
\text { velocity }\left(\omega_{\mathrm{e}}\right), \\
\mathrm{rad} / \mathrm{s}\end{array}$ & $\begin{array}{c}\text { Torque }(\mathrm{Te}), \\
\mathrm{N} \cdot \mathrm{m}\end{array}$ & Power(Pe), W \\
\hline 6 & 30 & 100 \\
\hline 9 & 30 & 200 \\
\hline 12 & 30 & 340 \\
\hline 15 & 30 & 440 \\
\hline
\end{tabular}




\begin{tabular}{|c|c|c|}
\hline 18 & 30 & 580 \\
\hline 21 & 30 & 680 \\
\hline 24 & 30 & 780 \\
\hline 27 & 30 & 890 \\
\hline 30 & 20 & 980 \\
\hline 33 & 10 & 1000 \\
\hline
\end{tabular}

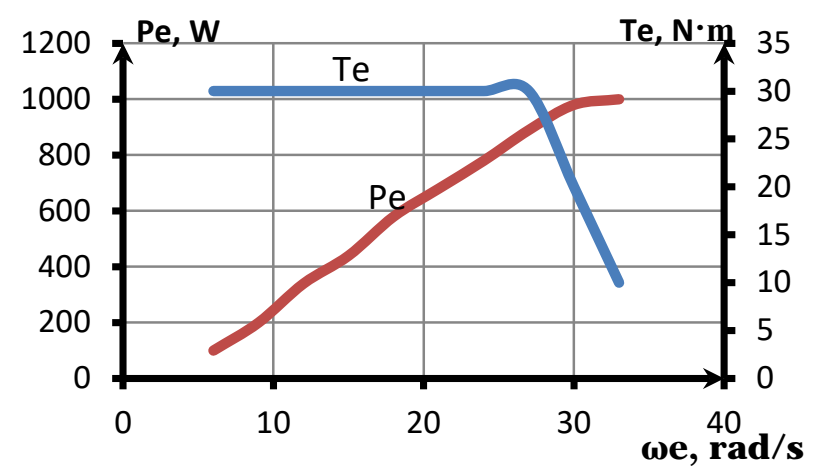

Fig. 5 Graph of the external speed characteristics of the bolide.

Next, determine the maximum speed (v) depending on the power and thrust $\left(\mathrm{F}_{\mathrm{t}}\right)$

$$
\mathrm{F}_{\mathrm{t}}=\frac{T_{e} \bullet i_{t r} \bullet \eta_{t r}}{r_{d}} \text {, where }
$$

$\mathrm{I}_{\mathrm{tr}}$ - the transmission ratio;

$\mathrm{H}_{\mathrm{tr}}$ - transmission efficiency;

$\mathrm{r}_{\mathrm{d}}$ - wheel radius, $\mathrm{m}$;

$\mathrm{F}_{\mathrm{f}}$ - rolling resistance force, $\mathrm{N}$;

$\mathrm{F}_{\mathrm{a}}$ - the force of air resistance, $\mathrm{N}$.

$$
v=3.6 \cdot \eta_{\mathrm{tr}} \cdot \frac{P_{e}}{F_{t}}
$$

Plot the Traction balance (traction Force from speed) (Fig. 6).

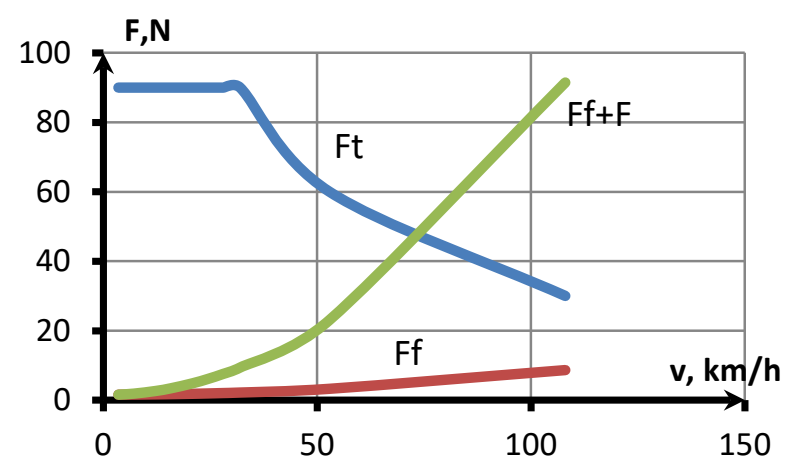

Fig. 6 Graph of the traction balance of the car.

According to the schedule, it can be concluded that the traction force on the electric motor has a maximum value from the beginning of the movement of the car, which gives an advantage over the internal combustion engine. At high speeds, the traction force is reduced, but at the Shell Eco Marathon race cars do not reach these speeds, which allows you to use the car in the most rational mode of traction.

By calculating the fairing factor, air resistance force (Fa) and rolling force $(\mathrm{Ff})$, to determine the respective capacities.

$$
\mathrm{Fa}=\mathrm{W} \cdot \mathrm{y}^{2} \text {, where }
$$

$$
\begin{aligned}
& \mathrm{W} \text { - flow factor }\left(\mathrm{N} \bullet \mathrm{s}^{2} / \mathrm{m}^{2}\right) \text {. } \\
& \qquad \mathrm{W}=\mathrm{C}_{\mathrm{x}} \bullet \rho \bullet \mathrm{A} / 2 \text {, where }
\end{aligned}
$$

$C_{X}$ - coefficient of aerodynamic resistance.

Determined experimentally. Accept $\mathrm{c}_{\mathrm{x}}=0.3$;

$\rho$ - air density. $\rho=1.225 \mathrm{~kg} / \mathrm{m}^{3}$;

A - the area of the midsection. Determined from a 3D model. $A=0.5 \mathrm{~m}^{2}$.

$$
\mathrm{Ff}=\mathrm{f} \bullet \mathrm{v}^{2} \text {, where }
$$

f- rolling resistance coefficient. Depends on the road surface. Accept $f=0.014$.

Determined by the Tractive power, the power of the air resistance and power of rolling resistance, build a chart of the balance of power (Fig. 7).

$$
\mathrm{Pt}=\mathrm{Ft} \bullet \mathrm{v}, \mathrm{Pf}=\mathrm{Ff} \bullet \mathrm{v}, \mathrm{Pa}=\mathrm{Fa} \bullet \mathrm{v}
$$

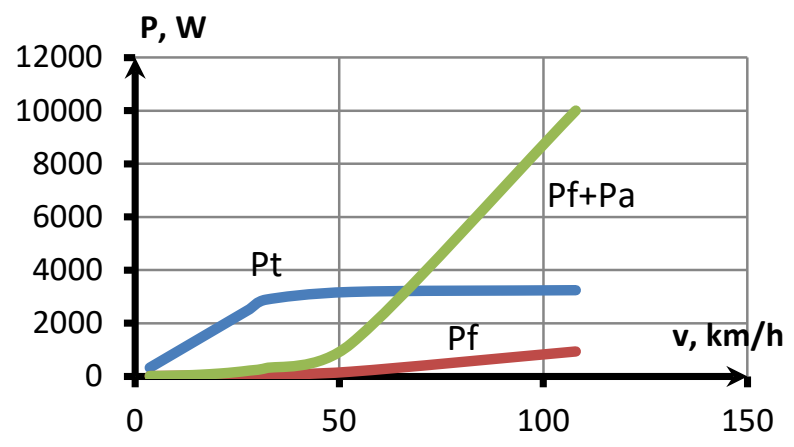

Fig. 7 Schedule of balance of power

Next, calculating the dynamic factor of the car, determine its acceleration.

$\mathrm{D}$ - dynamic factor.

$$
\mathrm{a}=\frac{(\mathrm{D}-\mathrm{f}) \cdot \mathrm{g}}{6} \text {, where }
$$

$$
\mathrm{D}=\frac{F_{t-F_{a}}}{m \cdot g} \text {, where }
$$

g- acceleration of gravity $=9.81 \mathrm{~m} / \mathrm{s}^{2}$;

6 - the coefficient accounting for rotating masses. Since the electric motor does not have a transmission and rotating masses in the engine itself, for the motor wheel we take the value $\sigma=1$

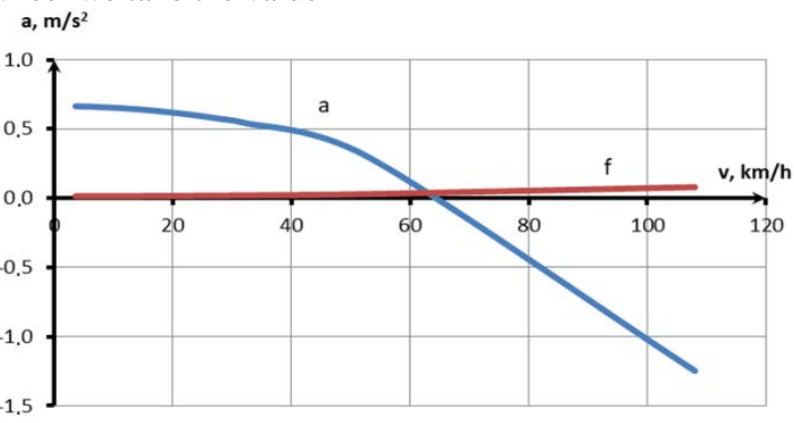

Fig. 8 Graph of acceleration of the car

The graph shows (Fig. 8) that the acceleration decreases slightly with increasing speed, demonstrating an advantage over internal combustion engines.

\section{Conclusions}

Based on the calculations, it can be concluded that the main parameter affecting the economy of the car is the capacity of the power plant [13]. However, if there is an insufficient power, the vehicle will not move and will not gain the necessary speed. Paying attention at 
the calculations, it can be established that the car, having a curb with the weight of $120 \mathrm{~kg}$ should be equipped with an engine with a capacity of $1 \mathrm{~kW}$ in order to achieve the greatest mileage on a given amount of electricity [14].

Another important quality for economy is the streamlining of the car [15-16]. Directly to the chassis - the monocoque of the car must be manufactured from non-metallic components, such as plastic or composite materials. Particular attention should be paid to composite materials, as this type of material has the necessary strength for the pilot's safety and a small mass at the same time. It should be noted that manufacturing of composite materials is a promising sphere that will eventually reduce production costs for the manufacture of such structural components.

The weight of the car carries an important component to increase the car's power reserve. Weight reduction may be achieved through the use of composites in the manufacturing of the cars frame and steering. It is worth considering that the materials used must have a high strength and rigidity that provide the necessary safety [17-19].

A particularly important function in the electric car is the battery. In this regard, it is necessary to pay attention not only to lithium-ion batteries, but also to promising developments-metal-air batteries, that have a lower mass and smaller size with a greater potential energy density. [20-22].

\section{References}

1. R. A. Fernández, A more realistic approach to electric vehicle contribution to greenhouse gas emissions in the city, Journal of Cleaner Production, 172 (2018)

2. R.C. Bansal, Electric vehicles, Handbook of Automotive Power Electronics and Motor Drives, (2017)

3. M. Moataz, R. Garnett, M. Ferguson, P. Kanaroglou. Electric buses: A review of alternative powertrain, Renewable and Sustainable Energy Reviews, 62 (2016)

4. E. Helmers, J. Dietz, Hartard S. Electric car life cycle assessment based on real-world mileage and the electric conversion scenario. The International Journal of Life Cycle Assessment, 22 (2017)

5. F. Del Pero, M.Delogu, M. Pierini, Life Cycle Assessment in the automotive sector: a comparative case study of Internal Combustion Engine (ICE) and electric car, 12 (2018)

6. P. Weldon, P. Morrissey, M. O'Mahony, Environmental impacts of varying electric vehicle user behaviours and comparisons to internal combustion engine vehicle usage - An Irish case study, Journal of Power Sources, 319 (2016)

7. P. Weldon, P. Morrissey, M. O'Mahony. Longterm cost of ownership comparative analysis between electric vehicles and internal combustion engine vehicles, Sustainable Cities and Society, 39 (2018)
8. R. A. Fernández, F. B. Cilleruelo, I. V. Martínez. A new approach to battery powered electric vehicles: A hydrogen fuel-cell-based range extender system, International Journal of Hydrogen Energy, 41 (8) (2016)

9. G. Wager, J. Whale, T. Braunl, Driving electric vehicles at highway speeds: The effect of higher driving speeds on energy consumption and driving range for electric vehicles in Australia, 63 (2016)

10. T. Gustafsson, A. Johansson, Comparison between battery electric vehicles and internal combustion engine vehicles fueled by electrofuels, Chalmers Tekniska (2015)

11. I. Kasatkin , M. Egorov , E. Kotov , E. Zakhlebaev, Cooling of a battery pack of a car, working on renewable energy (2018)

12. Y. Liu, D. Chen, Z. Lei, D. Qin, Y. Zhang, R. Wu, Y. Luo. Modeling and control of engine starting for a full hybrid electric vehicle based on system dynamic characteristics, International Journal of Automotive Technology, 18 (5) (2017)

13. S. Ionin, N. Korovkin, Prediction of currents and voltages alterations in transient modes of electric circuits based on reduced models (2016)

14. M. A. Grigor'ev, Synthesis of electric drives realizing limit operating regimes in terms of operation speed and overload capacity, Russian Electrical Engineering, 86 (12) (2015)

15. J. Han, A. Vahidi, A. Sciarretta, Fundamentals of energy efficient driving for combustion engine and electric vehicles: An optimal control perspective, Automatica, 103 (2019)

16. V. I. Vettegren, Stained state and wear resistance of polymer coatings, Physics of the Solid State, 57 (2015)

17. F. Larsson, P. Andersson, B. E. Mellander, Are electric vehicles safer than combustion engine vehicles? (2017)

18. S. Alekseev, Validation of Euroncap frontal impact of frame off-road vehicle: road traffic accident simulation, Materials Physics \& Mechanics, 34 (2017)

19. A. Ajanovic, The future of electric vehicles: prospects and impediments, Wiley Interdisciplinary Reviews: Energy and Environment, 4 (2015)

20. H. Fathabadi, Plug-In Hybrid Electric Vehicles: Replacing Internal Combustion Engine With Clean and Renewable Energy Based Auxiliary Power Sources, 33(11) (2018)

21. M. Elgamal, An Optimal Day-Ahead Operation Strategy for Hybrid Energy Microgrid, (EIConRus) (2019)

22. Y. Zhang, G. Peng, J. Banda, S. Dasgupta, M. Husband, An Energy Efficient Power Management Solution for a Fault-Tolerant More Electric Engine, 66(7) (2019) 